RESEARCH ARTICLE

\title{
Trematode infections in frogs: Do all cercarial morphotypes infect and induce effects on the common hourglass tree frog, Polypedates cruciger?
}

\author{
N.U.K. Pathirana and R.S. Rajakaruna*
}

Department of Zoology, University of Peradeniya, Peradeniya, Sri Lanka

Received:06/04/2018; Accepted:27/7/2018

\begin{abstract}
Trematodeinfections are known toinducemalformations and increase mortality in amphibians. However, not all the larval trematodes induce effects on the host. Nine types of cercariae (A-I) belonging to five morphotypes (oculopleurolophocercous, distome, gymnocephalous, xiphidiocercariae and pleurolophocercous) shed by the freshwater snail, Melanoides sp. were tested. Tadpoles of the common hourglass tree frog Polypedates cruciger at 10 days post-hatch (Gosner stage 27/28) were exposed to the cercariae in a mesocosm experiment. First exposure was carried out to identify which morphotypes induce effects on the host and later the exposures were repeated using selected cercariae, who induced effects on the host. Survival, growth and development of malformations were recorded in 15 and 30 days post-hatch tadpoles and metamorphs. Of the nine cercariae types, only three types., gymnocephalous (Type C) and two pleurolophocercous types ( $\mathrm{H}$ and $\mathrm{I}$ ), induced effects on the host with a single exposure. The repeated exposures showed that the cercariae type $\mathrm{H}$ significantly reduced the survival of tadpoles ( 4 replicates; Chi square test, $\chi^{2}=15.172, p<0.001$ ) but not the cercariae type I ( 7 replicates; $\chi^{2}=2.105, p=0.147$ ). Both cercariae types induced axial malformations such as kyphosis and scoliosis. The exposures incurred no changes to the size of tadpoles, but types $\mathrm{H}$ and I prolonged their growth period. Cercariae type $\mathrm{C}$ caused open wounds in the belly area of the host. This type of malformations has not been recorded in frogs before. However, cercariae type $\mathrm{C}$ was not shed by any of the snails collected later and therefore replicates were not carried out to confirm its effect. The results show that only some cercariae types induce effects on the frog host, possibly the cercariae types that use the tadpoles as the intermediate host to enter the definitive host and to complete its life cycle. Previous studies have reported two cercariae types induce frog malformations, hence collectively four cercariae types have demonstrated trematode induced effects on P. cruciger.
\end{abstract}

Keywords: trematode infections, amphibians, malformations, Polypedates cruciger.

\section{INTRODUCTION}

Many factors have been proposed to explain contemporary observations of malformed amphibians, including parasite infection, injuries from predation, chemical contaminants, ultraviolet (UV) B radiation, retinoids, ground-level ozone, radioactive mineral deposits, nutritional deficiencies, teratogenic viruses and fungi, acid precipitation, extreme temperatures (Ouellet, 2000; Blaustein and Johnson, 2003).Trematode infections of amphibians have attracted substantial attention because they are associated with mass mortality events (Johnson et al., 1999; Rohr et al., 2010), are believed to be more common now than historically (Johnson et al., 2003; Rohr et al., 2009; Wuerthner et al., 2017; Stutz et al., 2018) and can cause limb and body malformations (Johnson et al., 2012; Pathirana et al., 2016).

Trematodes have two or three hosts in their life cycle. Adult parasites live inside the definitive host (a vertebrate) and the eggs enter the environment through the faeces of the host. The eggs hatch into miracidia which penetrate a suitable intermediate host, a freshwater snail. Inside the snail, miracidia undergo asexual multiplication and become cercariae. Cercariae come out of the snail host and they either encyst on vegetation or in another animal (second intermediate host) or directly penetrate the definitive host and become the adult. Those who encyst become metacercariae and when the definitive host feed on the vegetation or the animal with the metacercariae, they reach the final host which is a vertebrate. Some cercariae encyst in amphibians. Upon encountering an amphibian, cercariae use proteolytic enzymes to encyst subcutaneously, where they can cause malformations in the developing amphibian (Sessions and Ruth, 1990; Johnson et al., 1999; Stopper et al., 2002). If an infected amphibian is consumed by a suitable vertebrate definitive host, metacercariae encyst and metamorphose, completing the life cycle (Koprivnikar et al., 2012). When cercariae of some trematode species develop into cysts, it interferes with the tadpole's metamorphosis into a frog. These cysts can disrupt the animal's normal development and induce high levels of direct mortality and malformations in amphibians on limbs, vertebral column, skin etc., which leads to indirect mortality by increasing the susceptibility to predation and thereby, the parasite successfully completes its lifecycle (Stopper et al., 2002).

Ribeiroia ondatrae (Trematoda: digenea) has been identified as the probable primary cause of hind limb malformations in Pacific tree frog Hyla regilla (Johnson et al., 1999, 2002) and Western toad Anaxyrus boreas (Johnson et al., 2001). Echinostomes are another group of trematodes which can cause tadpole mortality. Holland 
et al. (2007) suggested that echinostome infection is an emerging disease in green frogs (Rana clamitans) in urbanized environments.

Laboratory exposure of cercariae of a digenetic trematode, Acanthostomum burminis that infects water snakes causes high levels of malformations like scoliosis, kyphosis, edema and high levels of mortality in tadpoles and metamorphs of the common hourglass tree frog, Polypedates cruciger and the Asian common toad Duttaphrynus melanostictus (Rajakaruna et al., 2008; Jayawardena et al., 2010; 2013). The frequency of malformed individuals increased significantly with increasing doses of cercariae (Rajakaruna et al., 2008; Jayawardena et al., 2010b; 2013) when tadpoles were exposed to different doses of live cercariae $(0=$ control, 16=low, 32=medium, 48=high) following the method described by Johnson et al. (2001). Each tadpole was placed in a solid watch glass and the cercariae were introduced in four equal doses over four consecutive days (Rajakaruna et al., 2008). Cercariae-induced effects varied with the age of the host, with high mortality and fewer malformations at early pre-limb bud stage exposures (Jayawardena et al., 2010b) and high malformations and less mortality at later limb bud stage exposures (Rajakaruna et al., 2008). Malformed frogs have been observed in the wild as well. The first report of malformed frogs of Sri Lanka recorded specimens of an endemic monotype genus Lankanectes corrugatus and the common Rana temporalis from two protected areas with missing limbs and short bones and digits in the hind limb (Rajakaruna et al., 2007). Later, De Silva $(2008,2011)$ and Meegaskubura et al. (2011) have also reported malformed amphibians in the wild.

The present study was carried out in a mesocosm experimental set up to determine the effect on common hourglass tree frog, . cruciger when exposed to different cercariae morphotypes that are capable of infecting tadpoles and inducing effects. First, a preliminary experiment was carried out to identify which cercrial morphotypes should be used in a replicated, quantitative experiment. Then using those selected cercariae, replicate exposures were conducted.

\section{MATERIALS AND METHODS}

The common hourglass tree frog, Polypedates cruciger: the test species

Polypedates cruciger (Family Rhacophoridae) is a widely distributed endemic amphibian found in the Wet and the Dry zones of Sri Lanka up to $1525 \mathrm{~m}$ (Manamendraarachchi and Dutta, 1996). It is generally an arboreal species of secondary forest habitats, but can also occur in banana groves, loose barks, home gardens, houses and other buildings (IUCN, 2014). It is not present in primary forests, appears to be territorial often frequenting in small home ranges but has expanded its natural range of habitats as evidenced by the higher relative dominance in human modified environments (Pethiyagoda and Manamendraarachchi, 1998). It lays unpigmented eggs in a foam nest; clutch size varies from 240 to 300 eggs with an average diameter of $2.0 \mathrm{~mm}$ (Manamendra-arachchi and Dutta, 1996). The colour of adults can be greenish brown, dark brown or yellowish orange (Figure 1A). The frog also can change its body colour when exposed to varying intensities of light (Manamendra arachchi and Dutta 1996). This species is mostly threatened by agrochemical pollution and habitat destruction and alterations although the population trend of is stable and belongs to Least Concern (LC) category (IUCN, 2014).

\section{Collection of frog eggs and rearing of tadpoles}

Foamy egg masses of $P$. cruciger were collected from small pools and ponds in the Royal Botanical Gardens at Peradeniya $\left(7^{\circ} 16^{\prime} 16^{\prime \prime} \mathrm{N}, 80^{\circ} 35^{\prime} 44^{\prime \prime} \mathrm{E}\right)$ in the Central Province of Sri Lanka and brought to the laboratory in a cooler. The foam nest was attached to a leaf and hung on a glass container filled with dechlorinated tap water and the eggs were allowed to hatch under laboratory conditions (Figure 1B). After hatching, the tadpoles were transferred into glass tanks (measuring $15 \times 15 \times 25 \mathrm{~cm}$ ) containing $4 \mathrm{~L}$ of dechlorinated tap water and 20 tadpoles per tank ( 200mLof water per tadpole). Tadpoles were fed with fish pellets and lettuce. The feces and debris collected at the bottom of the tank were siphoned out daily and water

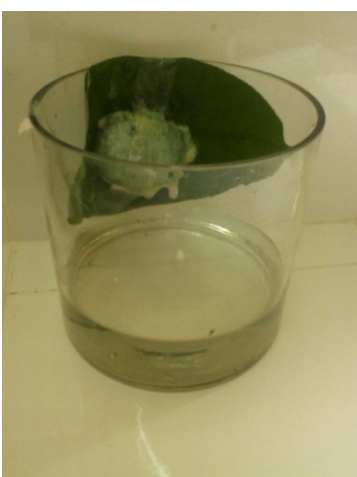

(A)

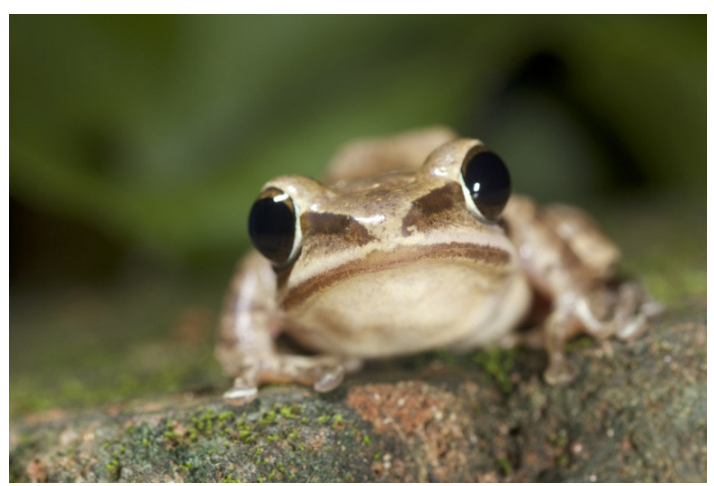

(B)

Figure 1: The common hourglass tree frog Polypedates cruciger A) Adult B) Foamy egg mass attached to a leaf. 
levels were replenished. Water in the tanks was completely replaced once a week. All the study protocols received ethical clearance from the Ethical Review Committee at the Postgraduate Institute of Science, University of Peradeniya, Sri Lanka.

\section{Collection of cercariae from snails}

Freshwater snails (Melanoides sp.; Figure 2) were collected from sandy bottoms of Maha-Oya in Kegalle district ( $7^{\circ} 15$ 1242 " N 80'26'47615” E) in the Central Province into glass bottles filled with water from the same habitat and were brought to the laboratory. Snails were kept separately in plastic cups containing $25 \mathrm{ml}$ of dechlorinated tap water. These plastic cups with snails were kept near the window to receive sunlight for $3-4 \mathrm{hrs}$ or exposed to an artificial light when there was no adequate sunlight to induce shedding of cercariae. This setup was left undisturbed in the laboratory for two days under room temperature $\left(27-30^{\circ} \mathrm{C}\right)$ until the snail started shedding cercariae. Each snail was observed under a dissecting microscope, several times a day for shedding of cercariae. The infected snails shedding a particular cercariae morphotype were separated and the other snails (snails with cross infections and noninfected) were released to the same habitat where they were collected. Daily renewal of the dechlorinated tap water medium was carried out to avoid $\mathrm{pH}$ changes in the medium. Cercariae released by the snails were isolated, slide mounted using Gilson's fixative and Borax Carmine single stain and morphotypes were identified according to Jayawardena et al. (2010a) and Yousif et al. (2010).

\section{Preliminary exposure of tadpoles to cercariae}

The plastic cup containing the snail that started shedding cercariae was covered with a net (Figure 3A) and was placed inside the glass tank containing 10 days posthatch tadpoles (Gosner stage $27 / 28$; Gosner, 1960) of $P$. cruciger (Figure 3B). The setup inside the tank resembled a natural pond containing aquatic plants, planktons, tadpoles and freshwater snails. A single snail, shedding one type of cercariae was introduced to a tank containing 20 tadpoles and control tank s were setup with 20 tadpoles from the same egg clutch without a snail. The control set up had the similar environment but without a snail. The plastic cup with a snail was kept inside a tank for two days allowing cercariae exposure and then the plastic cup was removed and the tadpoles were raised until metamorphosis. Survival, growth and development of malformations were observed in tadpoles at 15 and 30 days post-hatch and in the metamorphs following literature (Rajakruna et al., 2008, Jayawardena et al., 2010b). The cercairae types that induced effects on the tadpoles/metamorphs were separated and used in replicate exposures.

\section{Replicate exposures to cercariae}

In a similar set up, exposures were replicate using the cercariae that induced effects on the host. After the exposure, the tadpoles were individually examined under a dissecting microscope to observe the metacercariae cysts which were visible through the transparent skin tissues of the tadpole. The mortality of the tadpoles was noted down

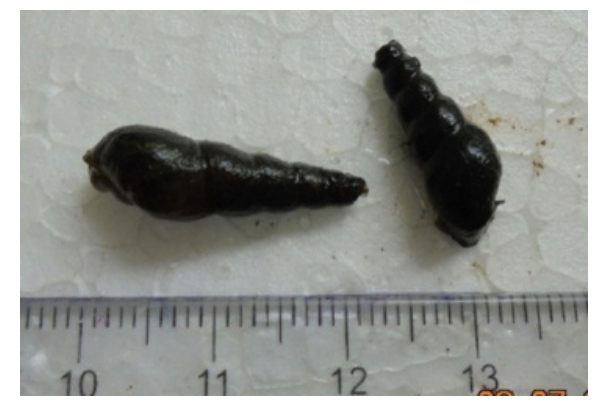

Figure 2: freshwater snail Melanoides $s p$. collected from sandy bottoms of Maha-Oya in Kegalle district.

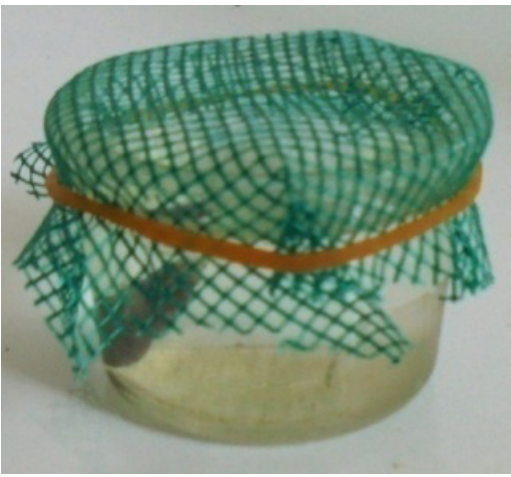

(A)

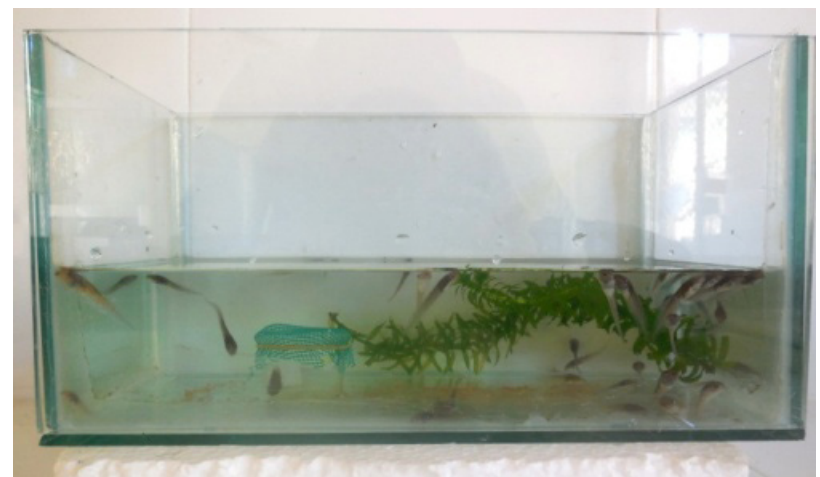

(B)

Figure 3: Experimental set up to expose tadpoles to cercariae. A) shows a freshwater snail shedding cercariea is placed inside a plastic cup covered with a mesh and B) shows the cup with the snail is being placed inside a glass tank containing twenty tadpoles of Polypedates cruciger at 10 days post-hatch (Gosner stage 27 / 28). 
daily and the growth of tadpoles in each experimental and control setups were measured as length and body mass in 15 and 30 days post-hatch tadpoles and in metamorphs. Length was measured by taking the snout-to-vent length (SVL; to the nearest $0.01 \mathrm{~cm}$ using a vernier caliper) and body mass (to the nearest $0.001 \mathrm{~g}$ using an electronic balance). Growth period was measured as the time required for fore-limb emergence of half of the number of tadpoles $\left(\mathrm{TE}_{50}\right)$. Malformations were recorded at 30 days post-hatch and at metamorphosis. Malformations observed in tadpoles and metamorphs were identified according to the "Field guide to malformations of frogs and toads" (Meteyer, 2000). These malformations were further categorized as limb malformations, vertebral column malformations and skin malformations. Malformed tadpoles and metamorphs were preserved in $70 \%$ alcohol. Skeleton of the malformed metamorphs were stained according to Newman et al. (1983).

\section{Statistical analysis}

Data from exposures of cercariae types $\mathrm{H}$ and I only were subjected to statistical analysis. The number of individuals that survived at 15 and 30 days post-hatch and at metamorphosis was compared with the control groups using a chi square test. The differences in growth parameters (SVL and body mass) between control and experimental setups with equal sample sizes were analysed using two way ANOVA (Analysis in Variance) and the differences in growth parameters (SVL and body mass) between control and experimental setups with unequal sample sizes were analysed using ANOVA General Linear Model. The differences in the time required for fore-limb emergence of half of the tadpoles $\left(\mathrm{TE}_{50}\right)$ between control and experimental setups were analysed using ANOVA General Linear Model. Results were analyzed using MINITAB 16.1 for Windows.

\section{RESULTS}

\section{Type of cercariae shed by snails}

A total of 70 freshwater snails belong to Melanoides sp. were collected and brought to the lab and of which 18 snails $(26.0 \%)$ released cercariae. Nine types of cercariae, belonging to five morphotypes were identified. Cercariae types included one distome, one oculopleurolo-phocercous type, three gymnocephalous types, two xiphidiocercariae, and two pleurolopho-cercous types (Figure 4). Each snail shed only one type of cercariae. All nine types were used to expose to tadpoles. The morphological description and swimming patterns of the cercariae morphotypes are as follows;

\section{Gymnocephalous type 1 (Figure 4A)}

Body is small $(\sim 300 \mu \mathrm{m})$ and oval shape with a relatively short tail $(\sim 120 \mu \mathrm{m})$. Body is light brown. Ventral sucker is small and located in the centre of the body. Swimming occurs by undulation of the body with the tail forming " $\mathrm{S}$ " shape and have relatively slow movements when compared with other two other types of Gymnocephalous cercariae. Most of the cercariae found at the bottom of the water column.

\section{Gymnocephalous type 2 (Figure 4C)}

Body is very small $(\sim 50 \mu \mathrm{m})$ and pear shape with a short tail $(\sim 20 \mu \mathrm{m})$. Relatively small when compared with two other types of Gymnocephalous cercariae. Body is transparent. Always found in the upper water column. Relatively fast movements.

\section{Gymnocephalous type 3 (Figure 4D)}

Body is oval shape $(\sim 350 \mu \mathrm{m})$ with a pointed tail $(\sim 300$ $\mu \mathrm{m})$. The tail is about the same length as the body. Body is brown colour. Move relatively fast and have circular movements unlike other two Gymnocephalous cercariae.

\section{Distome type (Figure 4B)}

Very small, oval shape body $(\sim 70 \mu \mathrm{m})$, connected to a long, slender tail $(\sim 100 \mu \mathrm{m})$. Body colour is transparent. Has relatively fast movements.

\section{Xiphidiocercous type 1 (Figure 4E)}

Oval transparent body $(\sim 250 \mu \mathrm{m})$ with a short tail $(\sim 100$ $\mu \mathrm{m})$. Oral sucker is not distinct. Ventral sucker is at the middle of the body. Has very slow movements when compared with the other Xiphidiocercous cercariae and mostly it can be found in the lower water column.

\section{Xiphidiocercous type 2 (Figure 4G)}

Oval, dark brown colour body $(\sim 150 \mu \mathrm{m})$ with a relatively short tail $(\sim 100 \mu \mathrm{m})$. Oral sucker is distinct. Ventral sucker is at the middle of the body. Have relatively fast circular movements unlike the Xiphidiocercous type 1.

\section{Pleurolophocercous type 1 (Figure 4H)}

Slender and oval shape, brown colour body $(\sim 300 \mu)$ with a long and slender tail $(\sim 500 \mu \mathrm{m})$. Oral sucker is prominent. Two circular eye spots can be found in the anterior part of the body. A pair of lateral fins can be found throughout the tail region in live specimens. Swimming is relatively fast with the tail forming " $\mathrm{S}$ " shape.

\section{Pleurolophocercous type 2 (Figure 4I)}

Slender,oval, transparent body $(\sim 250 \mu \mathrm{m})$ with a tail $(\sim 250$ $\mu \mathrm{m})$ approximately same length as the body. Tail is long and slender. Oral sucker is prominent. Two eye spots can be found in the anterior part of the body. A pair of lateral fins can be observed but unlike in Pleurolopho-cercous type 1 lateral fins can only be found in the anterior part of the tail in live specimens. The cercaria floats near the surface of water and falls to the bottom.

\section{Oculopleurolophocercous type (Figure 4F)}

Large oval transparent body $(\sim 1200 \mu \mathrm{m})$ with a very long tail $(\sim 3200 \mu \mathrm{m})$. Two small square shaped eyespots are located at the anterior region of the body. Lateral fin folds in the posterior region of the tail were visible in the live specimens. It has slow movements and sometimes crawls on the bottom. 


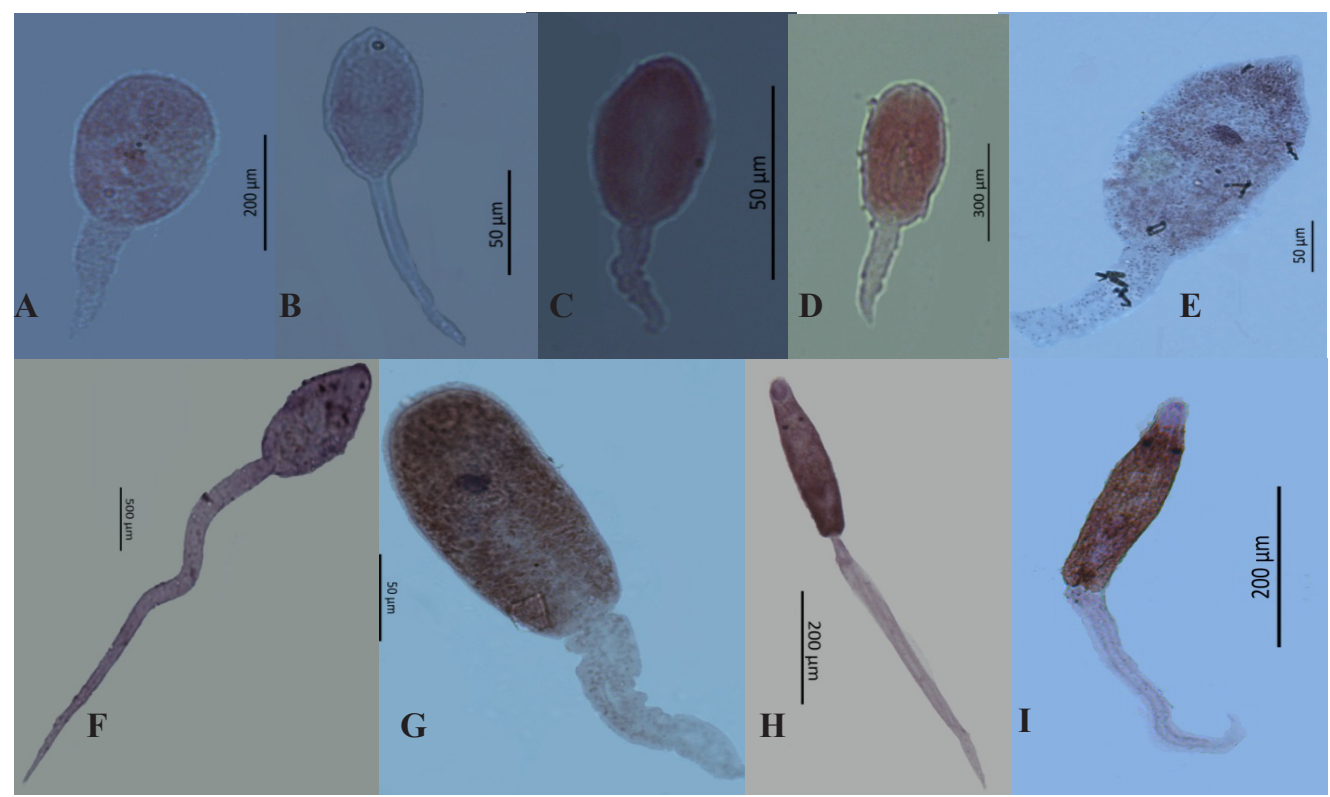

Figure 4: Types of cercariae found in the freshwater snail, Melanoides sp collected from sandy bottoms of Maha-Oya in Kegalle district A) Gymnocephalous type 1, B) Distome, C) Gymnocephalous type 2, D) Gymnocephalous type 3, E) Xiphidiocercous type 1, F) Oculopleurolophocercous; G) Xiphidiocercous type 2, H) Pleurolophocercous type 1 and I) Pleurolophocercous type 2.

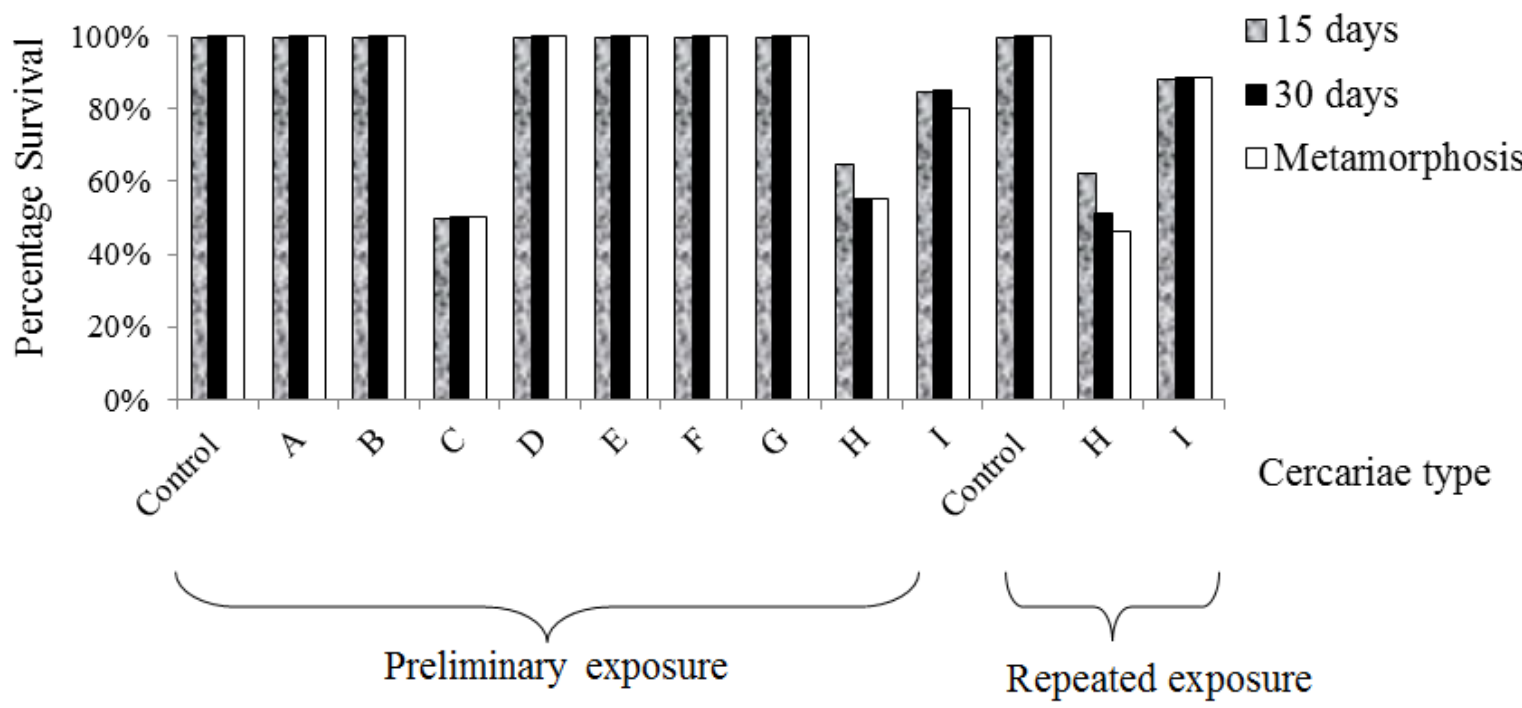

Figure 5: Percentage survival of tadpoles at 15 days post-hatch, 30 days post-hatch and at metamorphosis in the preliminary exposures to nine types of cercariae (A-I). Note: The percentages were taken by dividing the number of survived individuals (at a particular day) by the initial number of individuals.

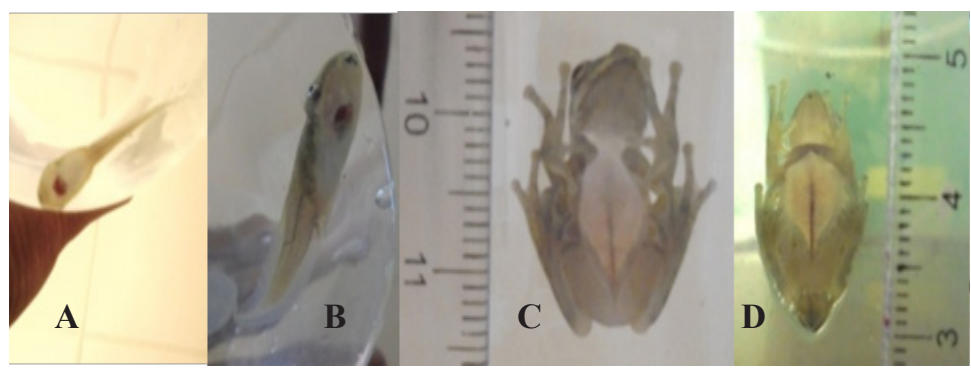

Figure 6: Tadpoles and metamorphs of $P$. cruciger exposed to cercariae type $C$ at Gosner stage 27/28. A and B) infected tadpole with a hole on the belly region in different stages of tadpole stage; C) uninfected metamorph; D) same infected metamorph; the hole developed into a stripe at the metermorphosis at 30/31 (A), 36 (B), 44/45 (D) Gosner stage, Complete metermorphosis (C). 


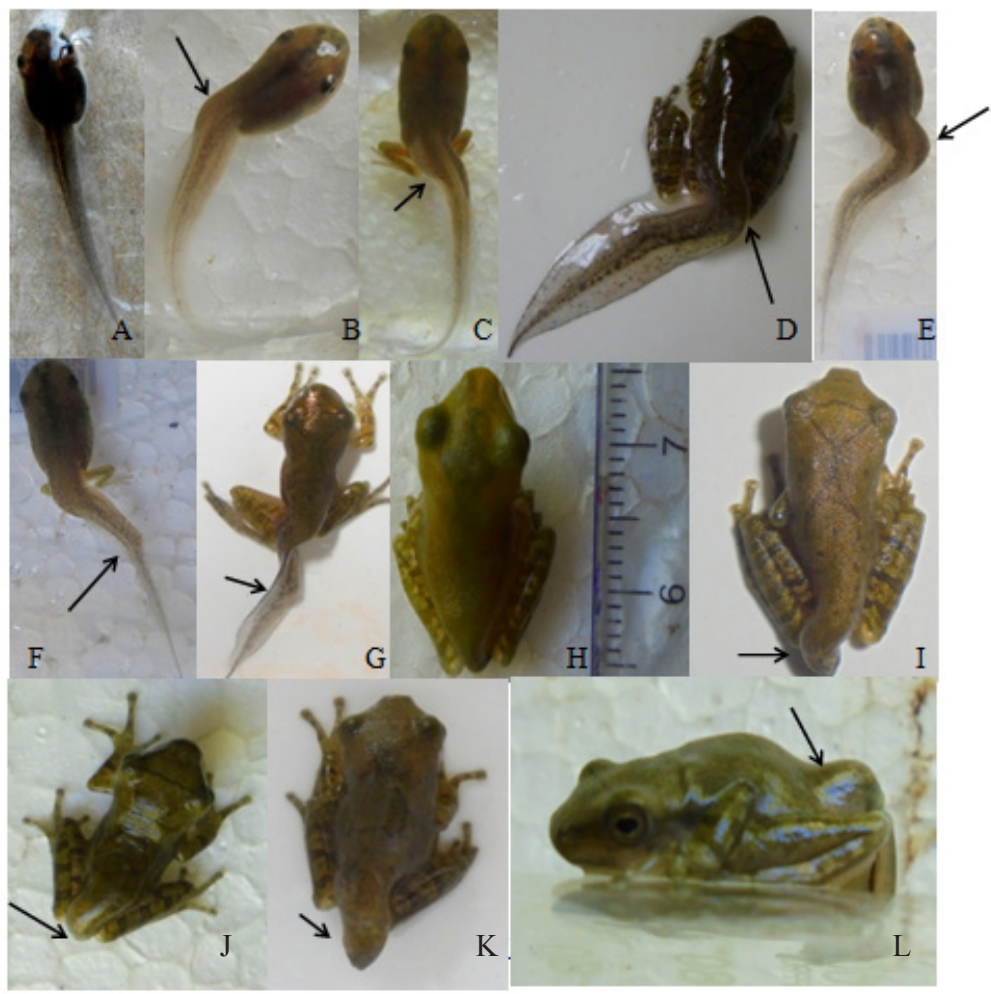

Figure 7: Tadpoles of Polypedates cruciger exposed to cercariae type H at Gosner stage 27/28. A) Uninfected normal tadpole; B to D) infected tadpoles at different developmental stages with kyphosis (hunched back or abnormal curvature of the spine in the dorso-ventral plane); E to G) with scoliosis (abnormal curvature of the spine in the lateral plane); H) normal metamorph; I and J) metamorphs with scoliosis (Note the malformation is absent in adult); $\mathrm{K}$ and $\mathrm{L}$ ) metamorphs with kyphosis at 30/31 (A,B,E), 38/39 (C,F), 41/42 (D,G),44/45(I,J,K) Gosner stages, Complete metermorphosis (H, L).

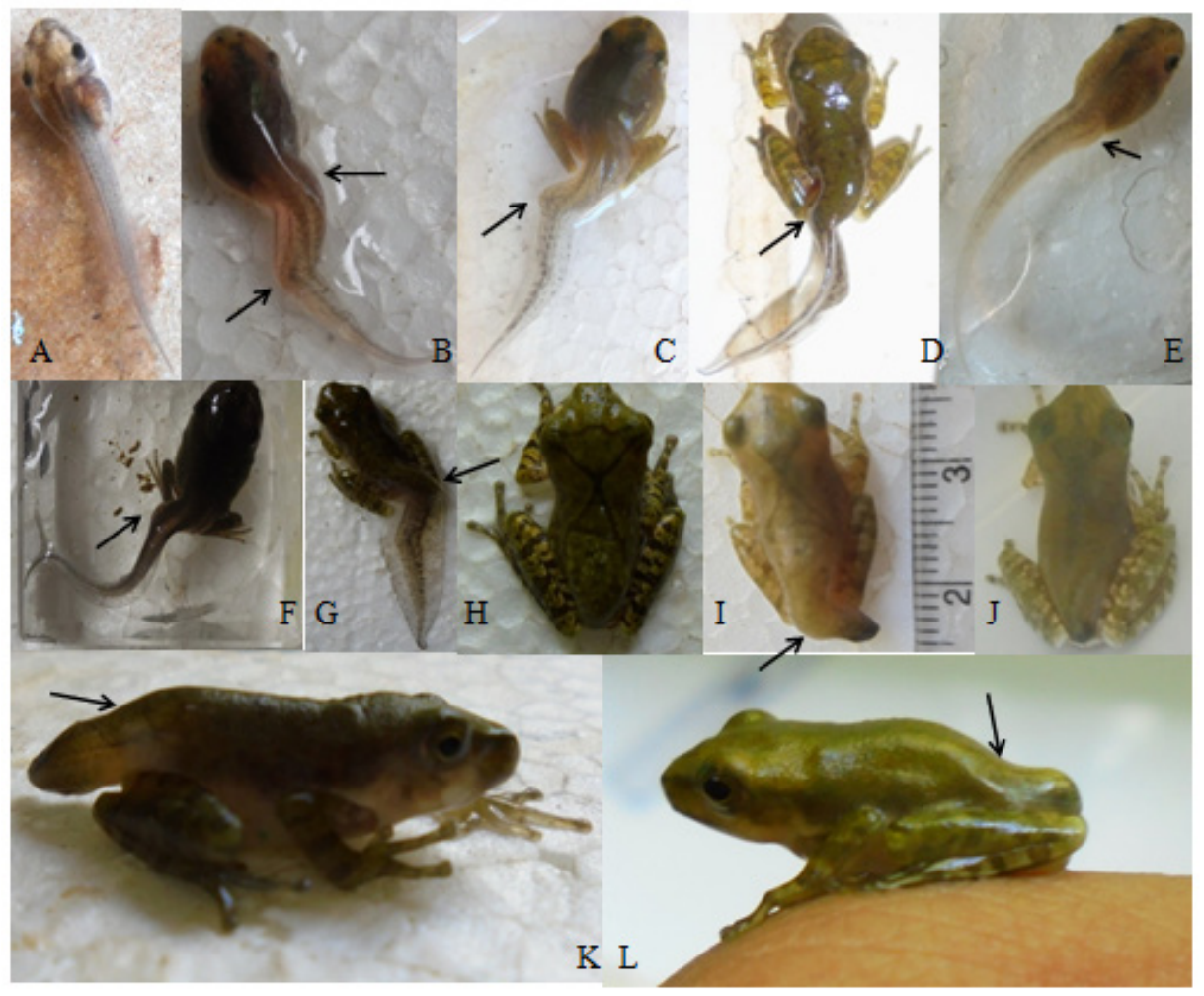

Figure 8: Tadpoles of P. cruciger exposed to cercariae type I at Gosner stage 27/28. A) Uninfected normal tadpole; B to D) infected tadpoles at different developmental stages with scoliosis E to G) kyphosis; H) normal metamorph; I and J) metamorphs with scoliosis (Note the malformation is absent in adult); $\mathrm{K}$ and $\mathrm{L}$ ) metamorphs with kyphosis at 30/31 (A,B,E), 38/39(C,F), 41/42 (D,G),44/45(I,K) Gosner stages, Complete metermorphosis (H, J, L) 
Table 1: Survival of tadpoles of Polypedates cruciger at 15 days, 30 days post-hatch and at metamorphosis after multiple exposure to cercariae types $\mathrm{H}$ and I (exposure at Gosner stage 27/28).

\begin{tabular}{|c|c|c|c|c|c|c|c|c|c|}
\hline & \multicolumn{3}{|r|}{ Control } & \multicolumn{2}{|c|}{ Cercariae type $\mathrm{H}$} & & \multicolumn{3}{|c|}{ Cercariae type I } \\
\hline & 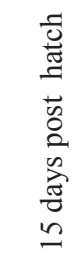 & 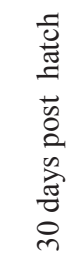 & 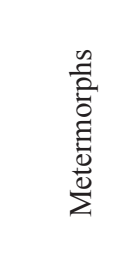 & 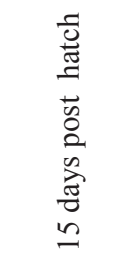 & 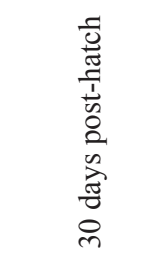 & 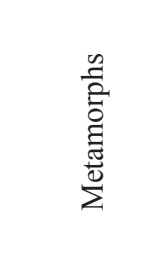 & 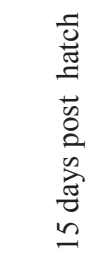 & 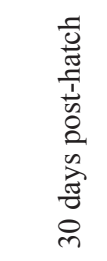 & 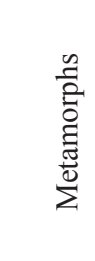 \\
\hline Survival \% & 100 & 100 & 100 & $62.5 \%$ & $51.3 \%$ & $46.0 \%$ & $88.5 \%$ & $88.5 \%$ & $88.5 \%$ \\
\hline$\chi^{2}$ & & - & - & 9.466 & 13.333 & 15.172 & 2.105 & 2.105 & 2.105 \\
\hline$p$ & - & - & - & $0.002 *$ & $<0.001^{* *}$ & $<0.001 * *$ & 0.147 & 0.147 & 0.147 \\
\hline
\end{tabular}

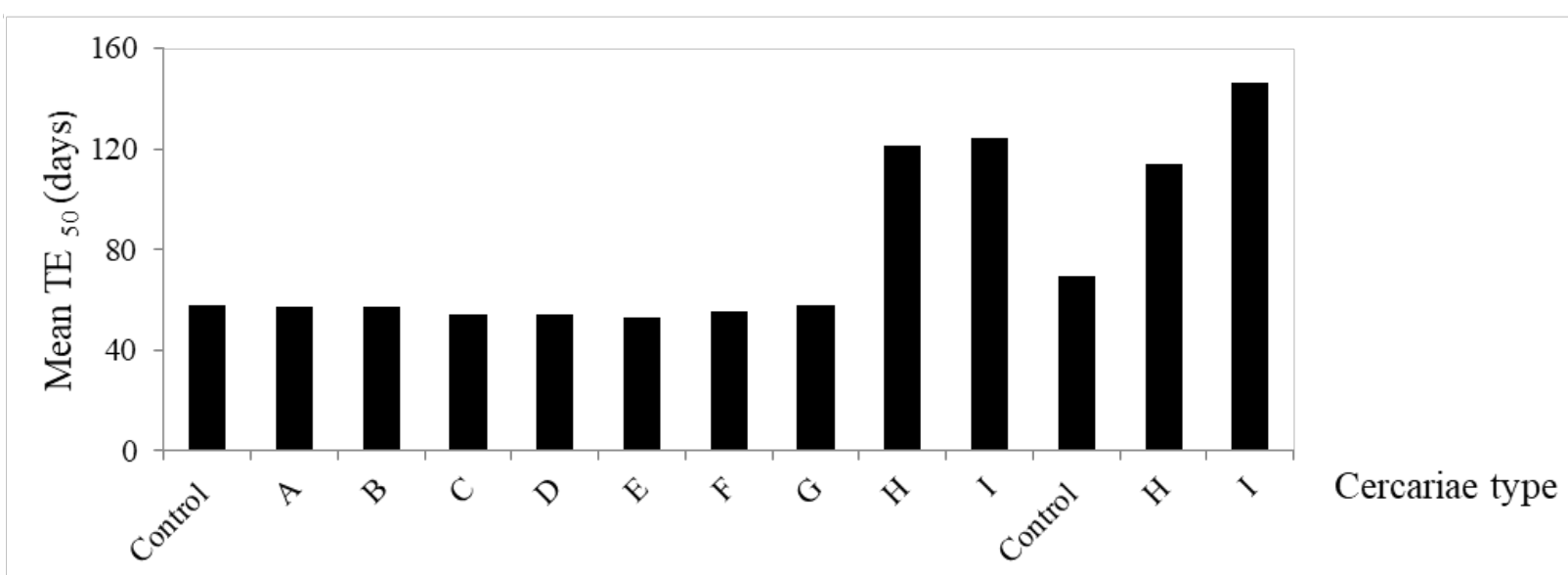

Figure 9: Time required for the forelimb emergence of half the number of tadpoles $\left(\mathrm{TE}_{50}\right)$ of Polypedates cruciger exposed to different types of cercariae (Cercariae types A to I) at Gosner stage 27/28 in the preliminary exposures and replicates.

\section{Preliminary exposure of tadpoles to cercariae}

The survival of the tadpoles and metamorphs in the control and those exposed to cercariae types A, B, D, E, F, and G was $100 \%$ (Figure 5). However, tadpoles exposed to cercariae types $\mathrm{C}, \mathrm{H}$ and $\mathrm{I}$ had a lower percentage of survival and these three cercariae also induced malformations. None of the tadpoles or metamorphs in the control or those exposed to other type of cercariae (A, B, D, E, F and G) developed any malformations. The malformation types observed in the tadpoles and metamorphs exposed to cercariae type $\mathrm{C}$ was an open wound in the belly area (Figure 6). However, the wound disappeared in some of the adults during metamorphosis. Cercariae type $\mathrm{H}$ and $\mathrm{I}$ induced axial malformations (Figures 7 and 8).

\section{Replicate experiments of selected cercariae}

Tadpoles were exposed to cercariae types H and I in four and seven replicates. However, we were unable to isolate the cercaraie type $\mathrm{C}$ from the snails during study period and thus, the replicates were not conducted.

\section{Survival of tadpoles and metamorphs}

The survival of the tadpoles exposed to cercariae type $\mathrm{H}$ decreased with time from $62.5 \%$ at 15 days post-hatch to $51.3 \%$ at 30 days post-hatch and then to $46.0 \%$ in the metamorphs (Table 1). The reduction is survival of tadpoles exposed to cercariae I was $88.5 \%$ at 15 days post-hatch, but further decrease was not observed thereafter (Figure 5). The reduction in survivorship of tadpoles exposed to cercariae type $\mathrm{H}$ was statistically significant compared to the control (Chi Square test, $p<0.05$ ) but not in the tadpoles exposed to cercariae type I (Chi Square test, $p>0.05$; Table 1 ).

\section{Growth of tadpoles and metamorphs}

Growth of the tadpoles (SVL and weight) measured at 15 and 30 days post-hatch and at metamorphosis is given in Table 2. There was no significant difference in the growth of tadpoles/ metamorphs of the exposed groups and those in the control (ANOVA General Linear Model, $p>0.05$ ). The time required for forelimb emergence of half the number of tadpoles $\left(\mathrm{TE}_{50}\right)$ in the exposed and control tadpoles is given in Figure 9. Tadpoles exposed to cercariae types $\mathrm{H}$ and I 
Table 2: Growth of tadpoles measured as body weight and snout to vent length of Polypedates cruciger at 15 days, 30 days posthatch and at metamorphosis after multiple exposure to cercariae types H and I (exposure at Gosner stage 27/28).

\begin{tabular}{|c|c|c|c|c|c|}
\hline \multirow[b]{2}{*}{$\begin{array}{c}\text { Cercariae } \\
\text { type }\end{array}$} & \multicolumn{3}{|c|}{ Mean weight \pm SD $(g)$} & \multirow[b]{2}{*}{$\boldsymbol{F}$} & \multirow[b]{2}{*}{$p$} \\
\hline & $\begin{array}{c}15 \text { days } \\
\text { post-hatch }\end{array}$ & $\begin{array}{c}30 \text { days } \\
\text { post-hatch }\end{array}$ & Metamorphs & & \\
\hline Control & $0.060 \pm 0.011$ & $0.069 \pm 0.011$ & $0.720 \pm 0.057$ & - & - \\
\hline $\mathrm{H}$ & $0.063 \pm 0.012$ & $0.066 \pm 0.011$ & $0.710 \pm 0.054$ & 0.59 & 0.444 \\
\hline I & $0.060 \pm 0.010$ & $0.064 \pm 0.012$ & $0.720 \pm 0.058$ & 1.26 & 0.262 \\
\hline \multicolumn{6}{|c|}{ Mean SVL \pm SD $(\mathrm{cm})$} \\
\hline Control & $0.62 \pm 0.166$ & $1.25 \pm 0.138$ & $1.74 \pm 0.109$ & - & - \\
\hline $\mathrm{H}$ & $0.61 \pm 0.175$ & $1.26 \pm 0.122$ & $1.70 \pm 0.117$ & 0.40 & 0.528 \\
\hline I & $0.60 \pm 0.152$ & $1.25 \pm 0.125$ & $1.74 \pm 0.105$ & 0.63 & 0.428 \\
\hline
\end{tabular}

Note $\mathrm{SD}=$ Standard deviation, Cercariae H had 4 replicates, Cercariae I had 7 replicates

Table 3: Percentages of malformations in P. cruciger exposed to cercariae types $\mathrm{H}$ and $\mathrm{I}$ at 30 days post-hatch stage and at metamorphosis (exposure at Gosner stage 27/28).

\begin{tabular}{|c|c|c|c|c|}
\hline \multirow{2}{*}{$\begin{array}{c}\text { Type of } \\
\text { malformation }\end{array}$} & \multicolumn{2}{|c|}{ Cercaria Type $\mathbf{H}$} & \multicolumn{2}{|c|}{ Cercaria Type I } \\
\hline & 30 days Post-hatch & Meta-morphs & 30 days post-hatch & Meta-morphs \\
\hline Kyphosis & $13.8 \%$ & $13.8 \%$ & $38.5 \%$ & $38.5 \%$ \\
\hline Scoliosis & $33.8 \%$ & $0.0 \%$ & $50.0 \%$ & $0.0 \%$ \\
\hline
\end{tabular}

Note: The percentages were taken by dividing the number of malformed individuals from the initial number (20 in cercariae types A to $\mathrm{G}, 80$ in cercariae type $\mathrm{H}$ and 140 in cercariae type I) of individuals exposed to each cercariae type at 30 days post-hatch stage and at metamorphosis.
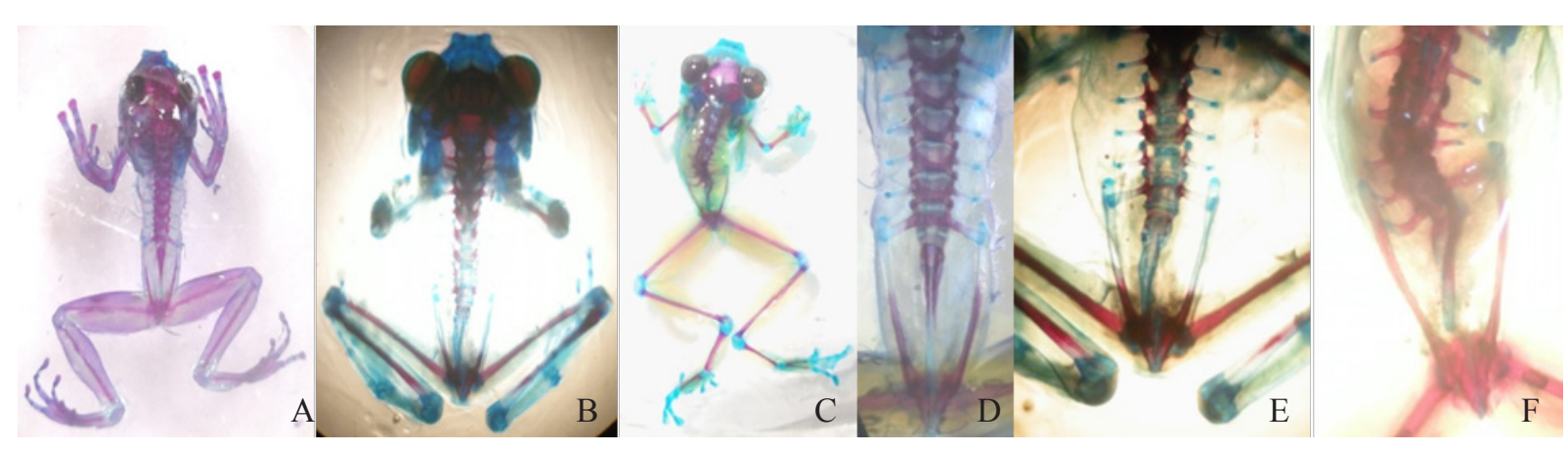

Figure 10: Stained skeletons of metamorphs of Polypedates cruciger. A and D) uninfected adult; B and E) adult with kyphosis. Note the twisted vertebral column; C and F) adult with scoliosis. Note the twisted urostyle region (Metamorphs with scoliosis did not show the malformation externally). 
had a significantly higher $\mathrm{TE}_{50}$ compared to the control (ANOVA General Linear Model, $F=23.94, p<0.001$ ).

\section{Malformations in tadpoles and metamorphs}

The malformation types observed in the tadpoles and metamorphs exposed to cercariae type $\mathrm{H}$ and I were axial including kyphosis (hunched back) and scoliosis (curvature of the spine) (Figure 7 and 8; Table 3). These were visible in the stained skeletons (Figure 10). Vertebral column and the urostyle region were different in metamorphs with kyphosis and scoliosis when compared with that of the uninfected metamorph. Although, scoliosis was observed in the tadpoles it was not externally present in the metamorph but was visible in the skeletons (Figure 10).

\section{DISCUSSION}

The results show that of the nine cercariae types, only three: gymnocephalous (Type C) and two pleurolophocercous types $(\mathrm{H}$ and $\mathrm{I})$ induced effects on the tadpoles of $P$. cruciger at limb-bud stage (Gosner stages 27/28). The cercariae type $\mathrm{H}$ significantly reduced the survival of tadpoles but the decrease in survival was not significant in cercariae type I exposed tadpoles. Both $\mathrm{H}$ and I cercariae types induced axial malformations such as kyphosis and scoliosis. The exposures did not have any effect on the size of the tadpoles, but exposed tadpoles had a prolonged growth period. During the preliminary exposures cercariae type $\mathrm{C}$ caused open wounds in the belly area of the host. This is a novel type of malformation that has not been recorded before. However, we were unable to isolate the same cercariae during the study period to replicate and confirm the findings. Many studies provide evidence for cercariae induced effects on amphibians. Cercariae of Acanthostomum burminis exposed to tadpoles of $P$. curciger and D. melanostictus induce different levels of mortality and malformations (Rajakaruna et al., 2008; Jayawardena et al., 2010b; Jayawardena et al., 2013). Cercariae of $R$. ondatrae induce severe malformations and high mortality in Hyla regilla, but exposure to cercariae of trematode species Alaria causes neither malformations nor an increase in mortality in the same frog species (Johnson et al., 1999). Thus, only some cercariae affect the amphibians and as Skelly et al. (2007) suggested the effect of cercariae on amphibians appears to be both parasite and host species specific. Identifying cercariae species in an ecosystem has a conservational importance since it provides predictions of negative consequences to the amphibian species in the same territory.

The tadpoles of $P$. cruciger exposed to cercariae types $\mathrm{H}$ had significantly lower survival $(46.0 \%)$. Reduced survival in tadpoles of $P$. cruciger exposed to cercariae of A. burminis have been reported at limb bud stage (survival $88.0 \%$; Rajakaruna et al., 2008) and at pre-limb bud stage (survival 77.5\%; Jayawardena et al., 2010b) and tadpoles of D. melanostictus exposed at pre-limb bud stage (survival 53.8\%; Jayawardena et al., 2013). Survival reductions have also been reported in other host species such as Bufo boreas, H. regilla, Rana pipiens exposed to $R$. ondatrae (Johnson et al., 2001; Johnson et al., 1999; Schotthoefer et al., 2003), R. clamitans exposed to Echinostoma sp. (Holland et al.,
2007). Mortality may be due to the encystment of cercariae causing hemorrhage, damage to the skin and degeneration of the tail musculature (Daszak et al., 2003). However, in the present study exposure to cercariae types A, B, D, E, F and G didn't reduce the tadpole survival. Similarly, Rana palustris tadpoles exposed to E. trivolvis does not show any reduction in the survival (Orlofske et al., 2009).

Malformations induced by cercariae types $\mathrm{H}$ and I were mainly seen in the axial region in the spine such as kyphosis (hunched back or abnormal curvature of the spine in the dorso-ventral plane) and scoliosis (abnormal curvature of the spine in the lateral plane). In the preliminary exposure cercariae type $\mathrm{C}$ induced a novel type of malformation, an open wound in the belly region. Malformations in limbs and spine greatly affect the movement of the amphibian. Malformations like kyphosis can be found in tadpole stages and after metamorphosis and that malformation can be observed externally. In contrast scoliosis is absent in all the adults externally although it was common among tadpole stages. However internal twisted urostyle region observed in the skeleton staining, indicates that scoliosis condition is present in metamorphs even though it cannot be observed externally. This malformed spine could be a disadvantage for a tree frog like P. cruciger, for hampering its movements (Rajakaruna et al., 2008). Furthermore, malformed tadpoles with scoliosis had difficulties in balancing their body when swimming. Severely malformed tadpoles were observed swimming upside down. Since the locomotion of malformed tadpoles and metamorphs both on land and water were impaired they will be highly susceptible to predation especially by water birds (like egrets, kingfishers) water snakes, etc. Open wound in the belly area can also cause indirect mortality of tadpoles and metamorphs and it may lead to viral, bacterial or fungus infections. The wound in the belly area make the tadpole or metermorph more lethargic and easy prey for the predators. Although the malformed tadpoles survived to metamorphose under the experimental conditions, they are vulnerable in the wild and are linked with indirect mortality due to increased predation (Sessions and Ruth, 1990). The most widely studied malformations of amphibians are limb, axial and skin malformations. Limb malformations like polymely, ectromely, polydactyly in tadpoles of B. boreas (Johnson et al., 2001) abnormalities in eyes, limb malformations like ectromely, polydactyly, polymely, ectrodactyly and skin malformations in tadpoles of $H$. regilla (Johnson et al., 1999) were reported when exposed to the cercariae of $R$. ondatrae. Tadpoles exposed to echinostome cercariae exhibited higher edema rates in $R$. clamitans (Holland et al., 2007). Edemas were also reported in P. cruciger and D. melanostictus exposed to A. burminis cercariae (Jayawardena et al. 2010b; 2013). Similar axial malformations were observed in the metamorphs of $P$. cruciger and D. melanostictus exposed to cercariae of $A$. burminis (Jayawardena et al., 2013; Rajakaruna et al., 2008). However, severe limb malformations similar to those observed in P. cruciger in Rajakaruna et al. (2008)and in the B. boreas, H. regilla, R. pipiens((Johnson et al., 2001; Johnson et al., 1999; Schotthoefer et al., 2003 and edemas observed in R. clamitans (Holland et al., 2007) were not observed in this study. Severity of the cercariae induced 
effects depends on the parasite dose and the number of cercariae penetrated in the present study is unknown and is expected to be lower due to the larger space in the tank like the individual exposures in a watch-glass. The mechanism through which cercariae interferes with amphibian spine development remains unknown. However, the axial malformations and open wound observed in this study may be due to a mechanical effect where the parasite disturbs the arrangement of vertebral column and skin tissue by chemical or physical disturbances-acting independently or in concert (Johnson et al., 2002).

Both cercariae types $\mathrm{H}$ and I didn't have any effect on growth of the tadpoles. Even in the treatments which had decreased survival also had no difference in growth although density-dependent effects on growth and size at metamorphosis have been observed in many amphibians, mainly due to stress (Petranka, 1989). However, tadpoles took more time to metamorphose than those in the control when exposed to cercariae $\mathrm{H}$ and I. The growth period measured by $\mathrm{TE}_{50}$ was significantly higher in the individuals exposed to cercariae type H (114.1 days) and I (146.2 days) compared to those in the control (69.5 days). Similar results were obtained in $P$. cruciger tadpoles, exposed to cercariae of A. burminis (Jayawardena et al., 2010b) and in D. melanostictus (Jayawardena et al., 2013). Those who metamorphosed early may have had fewer or no parasites as cercariae were not exposed to a fixed dose as done in previous studies (Rajakaruna et al., 2008; Jayawardena et al., 2010b; 2013).

Tadpoles of $P$. cruciger exposed to cercariae types $\mathrm{H}$ and $\mathrm{I}$ showed rapid swimming, twisting and wiggling behavior when the snail was placed inside the tank. These kinds of behaviors were not shown by the tadpoles exposed to cercariae types A, B, D, E, F and G and in the control groups.Further studies with individual exposures and dissections to observe metacercariae are needed to confirm whether the cercariae types A, B, D, E, F and G penetrate the host and whether the host shows tolerance and resistance to parasitism. Recent laboratory studies have shown that older tadpoles of $P$. cruciger show tolerance and resistance to parasitism by the trematode cercariae (Pathirana et al., 2016; 2017).

In nature amphibians and snails are found in the same ecosystem like a pond. This mesocosm study resembling a natural ecosystem showed that trematode infections could significantly affect amphibian survival and development of malformations in nature if the timing of cercarial shedding coincides with the most vulnerable stages of tadpole development. Previous studies recorded malformed frogs from the natural habitats in Sri Lanka (Rajakaruna et al., 2007; De Silva, 2008; 2011; Meegaskubura et al., 2011) some of these field recorded malformations are similar to those observed in this study.

\section{CONCLUSIONS}

This study provides evidence that two new cercariae types, $\mathrm{H}$ and $\mathrm{I}$ infect the frogs and induce significant effects on the tadpole host, hence collectively four cercariae isolated from freshwater snails in Sri Lanka have demonstrated trematode induced effects on $P$. cruciger. Further studies are required to confirm and quantify the effects induced by the cercariae type $\mathrm{C}$. The results also show that only some cercariae types induce effects on the frog host, possibly the cercariae types that use the tadpoles as the intermediate host to enter the definitive host and to complete its life cycle. Moreover, the importance of identifying the cercariae up to species level is highlighted.

\section{ACKNOWLEDGEMENT}

Financial support given by the National Science Foundation (NSF) Sri Lanka (Grant No. RG/2014/EB/02) is acknowledged.

\section{REFERENCES}

Blaustein, A.R. and Johnson, P.T.J. (2003). The complexity of deformed amphibians. Frontiers in Ecology and the Environment 1:87-94. doi/10.1890/15409295(2003)00 1\%5B0087: TCODA\%5D2.0.CO;2/full.

Daszak, P., Cunningham, A.A. and Hyatt, A.D. (2003). Infectious disease and amphibian population declines. Diversity and Distributions 9:141-150.

De Silva, A. (2008).2008 - Year of the Frog - Activities from Sri Lanka (27 October 2014).

De Silva, A. (2011). Some observations of malformation, eye disease, parasitic and viral infection and the effects of agrochemicals on amphibians in Sri Lanka. Available from: https://issuu.com/amphibiansdotorg/ docs/froglog98 (27 October 2014).

Gosner, K.L. (1960). A simplified table for staging anuran larvae with notes on identification. Herpetologica 16: 183-190; http://www.jstor.org/stable/3890061.

Holland, M.P., Skelly, D.K., Kashgarian, M., Bolden, S.R., Harrison LM and Cappello, M. (2007). Echinostome infection in green frogs (Rana clamitans) is stage and age dependent. Journal of Zoology 271: 455-462; http://onlinelibrary.wiley.com/doi/10.1111/j.14697998.2006.00229.x/full.

IUCN Red list for threatened species (2014).Polypedates cruciger.In: IUCN 2014. ( 02 November 2014).

Jayawardena, U.A., Amerasinghe, P.H. and Rajakaruna, R.S. (2010a). Cercariae of trematodes in freshwater snails in three climatic zones in Sri Lanka. Ceylon Journal of Science 39:95-108.

Jayawardena, U.A., Navaratne, A.N., Amerasinghe, P.H., Rajakaruna, R.S. and Tkach, V.V. (2013). Malformations and mortality in the Asian Common Toad induced by exposure to Pleurolophocercouscercariae (Trematoda: Cryptogonimidae). Parasitology International 62:246252; https://doi.org/10.1016/j.parint.2013.01.003.

Jayawardena, U.A., Navaratne, A.N., Amerasinghe, P.H. and Rajakaruna, R.S. (2010). Trematode induced malformations in amphibians: effect of infection at pre limb bud stage tadpoles of Polypedates cruciger Blyth. Journal of the National Science Foundation of Sri Lanka 38(4):241-248; http://doi.org/10.4038/jnsfsr. v38i4.2651.

Johnson, P.T.J., Lunde, K.B., Thurman, E.M., Ritchie, E.G., Wray, S.N., Sutherland, D.R., Kapfer, J.M., Frest, T.J., Bowerman, J. and Blaustein, A.R. (2002). Parasite 
(Ribeiroia ondatrae) infection linked to amphibian malformations in the Western United States. Ecological Monographs 72(2):151-168; doi:10.1890/00129615(2002)072[0151:PROILT]2.0.CO;2

Johnson, P.T.J., Lunde, K.B., Zelmer, D.A. and Werner, J.K. (2003). Limb deformities as an emerging parasitic disease in amphibians; evidence from museum specimens and resurvey data. Conservation biology 17(6):17241737; doi:10.1111/j.1523-1739.2003.00217.x

Johnson, P.T.J., Lunde, K.B., Haight, R.W., Bowerman, J. and Blaustein, A.R. (2001). Ribeiroia ondatrae (Trematoda: Digenea) infection induces severe limb malformations in Western toads (Bufo boreas). Canadian Journal of Zoology 79(3): 370-379; DOI: 10.1139/cjz-79-3-370.

Johnson, P.T.J., Rohr, J.R., Hoverman, J.T., Kellermanns, E., Bowerman, J. and Lunde, K.B. (2012). Living fast and dying of infection: host life history drives interspecific variation in infection and disease risk. Ecology Letters 15:235-242; 10.1111/j.14610248.2011.01730.x.

Johnson, P.T.J., Lunde, K.B., Ritchie, E.G. and Launer, A.E. (1999). The effect of trematode infection on amphibian limb development and survivorship. Science 284:802804; DOI: $10.1126 /$ science.284.5415.802

Koprivnikar, J., Marcogliese, D.J., Rohr, J.R., Orlofske, S.A., Raffel, T.R. and Johnson, P.T.J. (2012). Macroparasite infections of amphibians: what can they tell us? EcoHealth 9: 342-360; https://doi.org/10.1007/ s10393-012-0785-3.

Manamendraarachci, K. and Dutta, S.K. (1996). The Amphibian Fauna of SriLanka. Colombo 8: Wildlife Heritage Trust of SriLanka. Vi+168pp.

Meegaskumbura, M., Bowatte, G., Manamendra-Arachchi, K. and Meegaskumbura, S. (2011). Amphibian Research in Sri Lanka. Available from https://www.researchgate. net/publication/259760269_Amphibian_Research_in_ Sri_Lanka(27 October 2014).

Meteyer, C.U. (2000). Field guide to malformations of frogs and toads with radiographic interpretations. USGS National Wildlife Health Centre. Available from: https://www.nwhc.usgs.gov/publications/fact_sheets/ pdfs/frog.pdf( 04 April 2014).

Newman, S., Dugan, T.S. and Dumont, J.N. (1983). A rapid and simple procedure for visualization of amphibian skeletons for teralogical studies. Transactions of the American Microscopical Society 102(3):300-305; doi: $10.2307 / 3225837$.

Orlofske, S.A, Belden, L.K. and Hopkins, W.A. (2009). Moderate Echinostoma trivolvis infections has no effects on physiology and fitness related traits of larval pickerel frogs.(Rana palustris). The Journal of Parasitology 95(4):787-792; https://doi.org/10.1645/ GE-1840.1.

Ouellet, M. (2000). Amphibian deformities: current state of knowledge. In: Sparling, D.W., G. Linder and C.A. Bishop (eds.) (2000). Ecotoxicology of Amphibians and Reptiles. Society of Environmental Toxicology and Chemistry, Pensacola, Florida.

Pathirana, N.U.K., Meegaskubura, M. and Rajakaruna, R.S. (2016). Age dependant tolerance to parasitism:
Trematode infections of tadpoles of common hourglasstree frog Polypedates cruciger. Peradeniya University International Research Sessions (iPURSE) 20 p.299.

Pathirana, N.U.K., Meegaskumbura, M. and Rajakaruna, R.S. (2017) Host resistance to parasitism: Do older tadpoles of Polypedates cruciger show higher resistance towards pleurolophocercous cercariae? International Forestry and Environment Symposium, University of Sri Jayawardenapura, 22 p 22.

Pethiyagoda, R. and Manamendra-Arachchi, K.(1998). Evaluating Sri Lanka's amphibian diversity. Occasional papers of the Wildlife HeritageTrust. No2:1-12.

Petranka, J.W. (1989). Density-dependent growth and survival of larval Ambystoma: evidence from whole-pond manipulations. Ecology 70: 1752-1767; $10.2307 / 1938109$.

Rajakaruna R.S, Piyatissa, P.M.J.R., Jayawardena UA, Navaratne A.N. and Amerasinghe P.H. (2008) .Trematode infection induced malformations in the common hourglasstree frogs. Journal of Zoology 275(1): 89-95; doi:10.1111/j.1469-7998.2008.00416.x

Rajakaruna, R.S, Samarawickrama, V.A.M.P.K. and Ranawana, K.B. (2007). Amphibian declines and possible etiologies: the case for Sri Lanka. Journal of the National Science Foundation of Sri Lanka 35(1): 3-8.

Rohr, J.R., Raffel, T.R. and Hall, C.(2010). Developmental variation in resistance and tolerance in a multi-hostparasite system. Functional Ecology 24(5):1110-1121; 10.1111/j.1365-2435.2010.01709.X

Rohr, J.R, Raffel, T.R. and Sessions, S.K.(2009). Digenetic trematodes and their relationship to amphibian declines and deformities. Amphibian Biology 8: 3067-3088.

Schotthoefer, A.M, Koehler, A.V , Meteyer, C.U. and Cole, R.A. (2003). Influence of Ribeiroia ondatrae (Trematoda: Digenea) infection on limb development and survival of northern leopard frogs (Rana pipiens): effects of host stage and parasite exposure level. Canadian Journal of Zoology 81:1144-1153; https:// doi.org/10.1139/z03-099.

Sessions, S.K. and Ruth, S.B. (1990). Explanation of naturally occurring supernumerary limbs in amphibians. The Journal of Experimental Zoology 254: 38-47;10.1002/jez.1402540107.

Skelly, D.K., Bolden, S.R., Freidenburg, L.K., Freidenburg, N.A. and Levey, R. (2007). Ribeiroia infection is not responsible for vermont amphibian deformities. EcoHealth 4:156-163; https://doi.org/10.1007/s10393007-0103-7.

Stopper, G.F., Hecker, L., Franssen, R.A. and Sessions, S.K. (2002). How trematodes cause limb deformities in amphibians. The Journal of Experimental Zoology 294:252-263; https://doi.org/10.1002/jez.10173.

Stutz, W.E., Blaustein, A.R., Briggs, C.J., Hoverman, J.T., Rohr, J.R. and Johnson, P.T.J. (2018) Using multiresponse models to investigate pathogen coinfections across scales: Insights from emerging diseases of amphibians Methods Ecology and Evolution 9:11091120 .

Wuerthner, V.P., Hua, J., and Hoverman, J.T. (2017). 
The benefits of coinfection: Trematodes alter disease outcomes associated with virus infection. Journal of Animal Ecology, 86, 921-931. https://doi. org/10.1111/1365-2656.12665.

Yousif, F., Ibrahim, A., Bardicy, S., Sleem, S. and Ayoub, M. (2010). Morphology of New Eleven Cercariae Procured from Melanoides tuberculata Snails in Egypt. Australian Journal of Basic and Applied Sciences 4(6): 1482-1494. 